NASA/TM-2011-216983

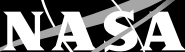

Seeding Cracks Using a Fatigue Tester for Accelerated Gear Tooth Breaking

Nenad G. Nenadic, Joseph A. Wodenscheck, and Michael G. Thurston

Rochester Institute of Technology, Rochester, New York

David G. Lewicki

Glenn Research Center, Cleveland, Ohio 


\section{NASA STI Program . . . in Profile}

Since its founding, NASA has been dedicated to the advancement of aeronautics and space science. The NASA Scientific and Technical Information (STI) program plays a key part in helping NASA maintain this important role.

The NASA STI Program operates under the auspices of the Agency Chief Information Officer. It collects, organizes, provides for archiving, and disseminates NASA's STI. The NASA STI program provides access to the NASA Aeronautics and Space Database and its public interface, the NASA Technical Reports Server, thus providing one of the largest collections of aeronautical and space science STI in the world. Results are published in both non-NASA channels and by NASA in the NASA STI Report Series, which includes the following report types:

- TECHNICAL PUBLICATION. Reports of completed research or a major significant phase of research that present the results of NASA programs and include extensive data or theoretical analysis. Includes compilations of significant scientific and technical data and information deemed to be of continuing reference value. NASA counterpart of peer-reviewed formal professional papers but has less stringent limitations on manuscript length and extent of graphic presentations.

- TECHNICAL MEMORANDUM. Scientific and technical findings that are preliminary or of specialized interest, e.g., quick release reports, working papers, and bibliographies that contain minimal annotation. Does not contain extensive analysis.

- CONTRACTOR REPORT. Scientific and technical findings by NASA-sponsored contractors and grantees.
- CONFERENCE PUBLICATION. Collected papers from scientific and technical conferences, symposia, seminars, or other meetings sponsored or cosponsored by NASA.

- SPECIAL PUBLICATION. Scientific, technical, or historical information from NASA programs, projects, and missions, often concerned with subjects having substantial public interest.

- TECHNICAL TRANSLATION. Englishlanguage translations of foreign scientific and technical material pertinent to NASA's mission.

Specialized services also include creating custom thesauri, building customized databases, organizing and publishing research results.

For more information about the NASA STI program, see the following:

- Access the NASA STI program home page at http://www.sti.nasa.gov

- E-mail your question via the Internet to help@ sti.nasa.gov

- Fax your question to the NASA STI Help Desk at $443-757-5803$

- Telephone the NASA STI Help Desk at 443-757-5802

- Write to: NASA Center for AeroSpace Information (CASI) 7115 Standard Drive Hanover, MD 21076-1320 
NASA/TM-2011-216983

NESE

Seeding Cracks Using a Fatigue Tester for Accelerated Gear Tooth Breaking

Nenad G. Nenadic, Joseph A. Wodenscheck, and Michael G. Thurston

Rochester Institute of Technology, Rochester, New York

David G. Lewicki

Glenn Research Center, Cleveland, Ohio

Prepared for the

IMAC XXIX A Conference and Exposition on Structural Dynamics

sponsored by the Society for Experimental Mechanics (SEM)

Jacksonville, Florida, January 31 to February 3, 2011

National Aeronautics and

Space Administration

Glenn Research Center

Cleveland, Ohio 44135 


\section{Acknowledgments}

This work was made possible by Army Research Laboratory under Award No. W911NF-07-2-0080. We gratefully acknowledge the help of our colleagues from Rochester Institute of Technology Dr. Michael Haselkorn, David Fister,

Michael Leaty, and Dominic Maiola for their assistance in destructive crack assessment; Mark Walluk and Michael Bradley for design of the crack initiation fixture; and Art Dee LabVIEW for implementation of the crack detection.

Trade names and trademarks are used in this report for identification only. Their usage does not constitute an official endorsement, either expressed or implied, by the National Aeronautics and Space Administration.

Level of Review: This material has been technically reviewed by technical management.

Available from

NASA Center for Aerospace Information 7115 Standard Drive

Hanover, MD 21076-1320
National Technical Information Service 5301 Shawnee Road Alexandria, VA 22312

Available electronically at http://www.sti.nasa.gov 


\title{
Seeding Cracks Using a Fatigue Tester for Accelerated Gear Tooth Breaking
}

\author{
Nenad G. Nenadic, Joseph A. Wodenscheck, and Michael G. Thurston \\ Rochester Institute of Technology \\ Rochester, New York 14623 \\ David G. Lewicki \\ National Aeronautics and Space Administration \\ Glenn Research Center \\ Cleveland, Ohio 44135
}

\begin{abstract}
This report describes fatigue-induced seeded cracks in spur gears and compares them to cracks created using a more traditional seeding method, notching. Finite element analysis (FEA) compares the effective compliance of a cracked tooth to the effective compliance of a notched tooth where the crack and the notch are of the same depth. In this analysis, cracks are propagated to the desired depth using FRANC2D and effective compliances are computed in ANSYS. A compliance-based feature for detecting cracks on the fatigue tester is described. The initiated cracks are examined using both nondestructive and destructive methods. The destructive examination reveals variability in the shape of crack surfaces.
\end{abstract}

\section{Background of the Study}

Of the four dominant modes of gear tooth failure (breakage, wear, pitting, and scoring), breakage is the most catastrophic and occurs precipitously, with no advanced warning. The present study is concerned with the breakage failure mode exclusively.

The work described here is a subset of a larger empirical study conducted on high-quality spur gears to evaluate performance of vibration-based features for detecting cracks and assessing crack depths. The features, also referred to as condition indicators (CIs), are summarized by References 1 to 3 .

In this larger study, the gears are first spun in a dynamometer-based fixture to obtain feature baselines. The cracks are then initiated using a fatigue tester to simulate overload conditions. Finally, the fatigue induced-cracks are propagated on the dynamometer-based fixture under different operating conditions, i.e., different levels of angular speed and torque, while the actual crack length on each gear face is measured using crack-propagation sensors. The main objective is to create well-documented, statistically significant data for monitoring cracks from inception to failure.

The complete service life of a gear has two phases: crack initiation and crack propagation (Ref. 4). A crack initiation phase is typically much longer than the subsequent crack propagation phase. In crack propagation studies, the crack initiation phase is often accelerated by introducing a notch in a gear tooth. The present article describes an alternative approach to accelerate crack initiation where higher-thannormal loads are applied on a gear tooth using a fatigue tester.

\section{Finite Element Analysis (FEA) of a Cracked and a Notched Tooth}

Before proceeding with accelerated crack initiation on a fatigue tester, it was of interest to compare the geometry of cracked and notched gear teeth. A gear with a notch was compared to a gear with a crack of the same length as the notch using FEA. The gear geometry was generated using a toolkit implemented in MATLAB for spur gear drawing and analysis, as shown in Figure 1. The first version of the software was created by Reference 5 and implemented by the Army Research Laboratory and NASA in Fortran. The present version is implemented by RIT, with added capabilities that include mesh generation and import and 


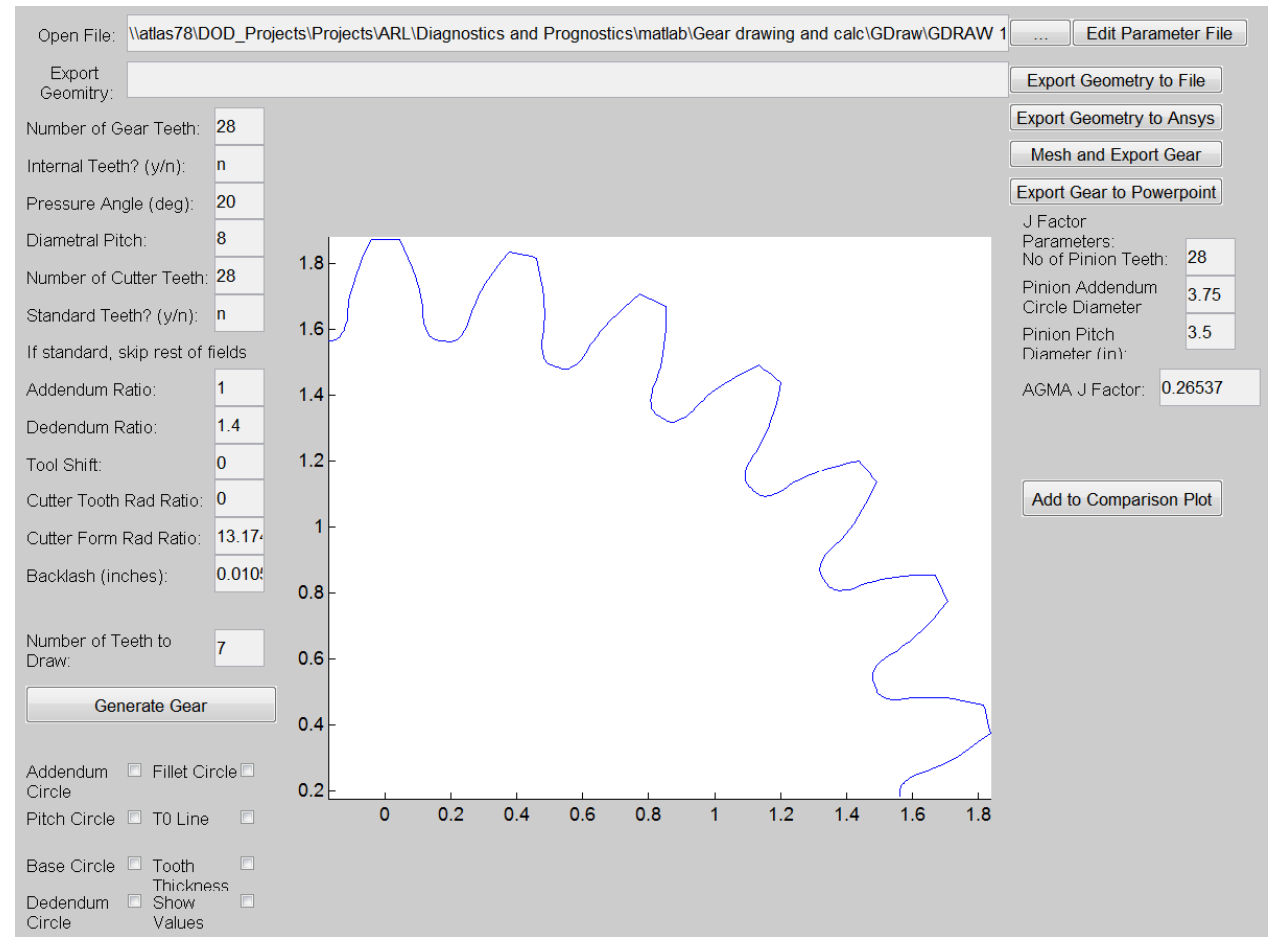

Figure 1.-Spur gear geometry generation.
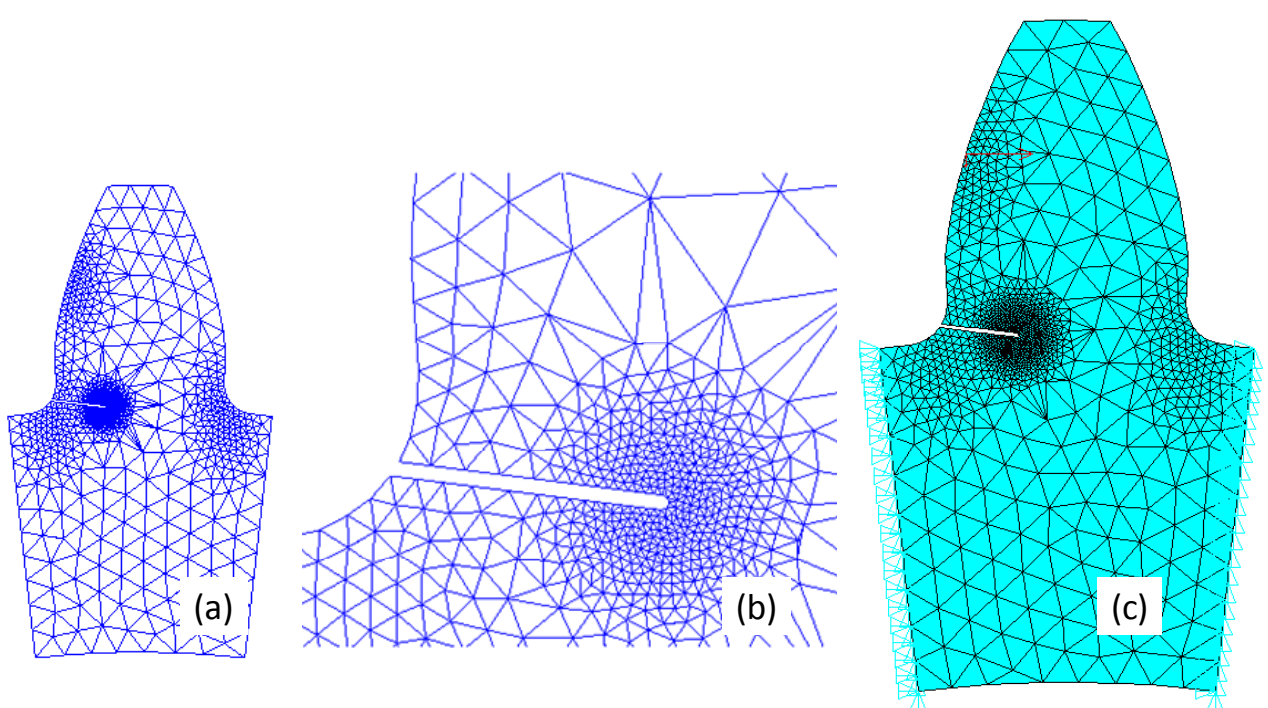

Figure 2.-A notched tooth generation within the MATLAB-based toolkit. (a) Entire tooth geometry using MATLAB. (b) Zoom into crack using MATLAB. (c) Notch exported into ANSYS.

export capabilities. The toolkit is capable of generating the gear tooth geometry, creating a finite element mesh using linear triangular elements, and exporting the meshed geometry to two commercially available finite element programs, FRANC2D and ANSYS. The mesh generator employs the distmesh algorithm and implementation (Ref. 6). The implementation is tailored to generate finer mesh near the application of force and high stress areas. Figure 2 shows the meshed geometry of a notched tooth, with nonuniform mesh density, generated entirely within the toolkit. The generation of the cracked tooth is a bit more involved. The uncracked tooth geometry is generated in the MATLAB toolkit. The geometry is then exported to FRANC2D, a program for simulation of crack growth (Ref. 7) where the initial crack was formed and propagated to the desired length. The cracked geometry is then read and exported to ANSYS via the MATLAB toolkit. 
Figure 3 shows ANSYS static analysis of a gear with a notch, and a gear with a crack. The view is zoomed into the area of notch/crack. To minimize the difference in the crack length and the notch length, we generated the cracked geometry first, and then generated the notch later by aligning the tip of the notch to the tip of the crack.

In the first analysis, a static force of $1000 \mathrm{lb}$ was applied at the gear pitch radius, normal to the surface, and the magnitude of the displacement was measured at the tip of the outer radius, as depicted in Figure 4(a). The simulation was repeated for two crack/notch lengths: $\approx 1 / 8$ of the total gear thickness and $\approx 1 / 4$ of the total gear thickness. Two notch sizes were studied. One for a notch radius of $\mathrm{R}=0.001 \mathrm{in}$., and the other for a notch radius of $\mathrm{R}=0.002 \mathrm{in}$. The effect of mesh density on the result for the cracked tooth was also considered. Although we computed displacements, the results can be expressed also as effective compliances, since the force is held constant.

The FEA results are summarized in Table 1 and Figure 4(b). For the crack/notch length of 1/8 of the gear thickness all the displacements are virtually indistinguishable, they are within less than 0.2 percent of the mean. For a crack/notch length equal to $1 / 4$ of gear thickness, the notched gear exhibits larger displacements.

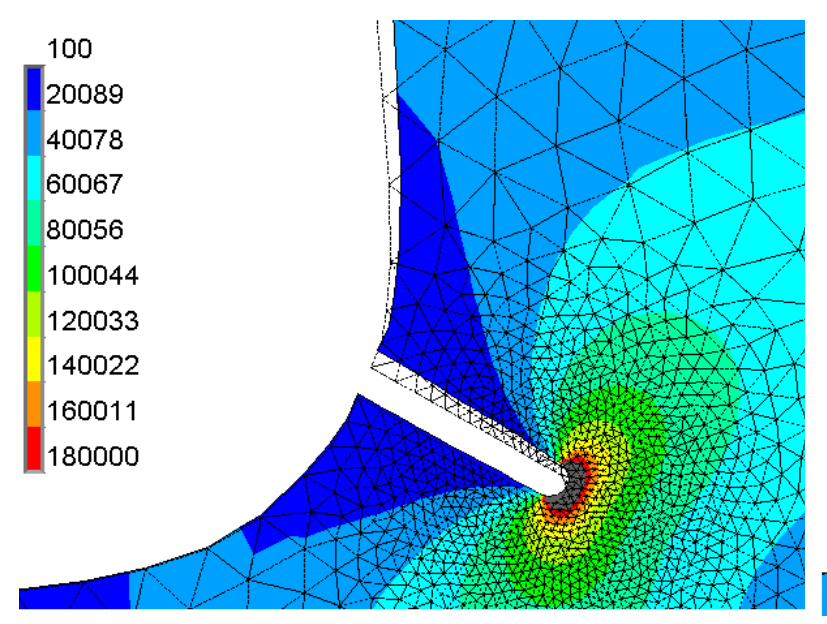

(a)

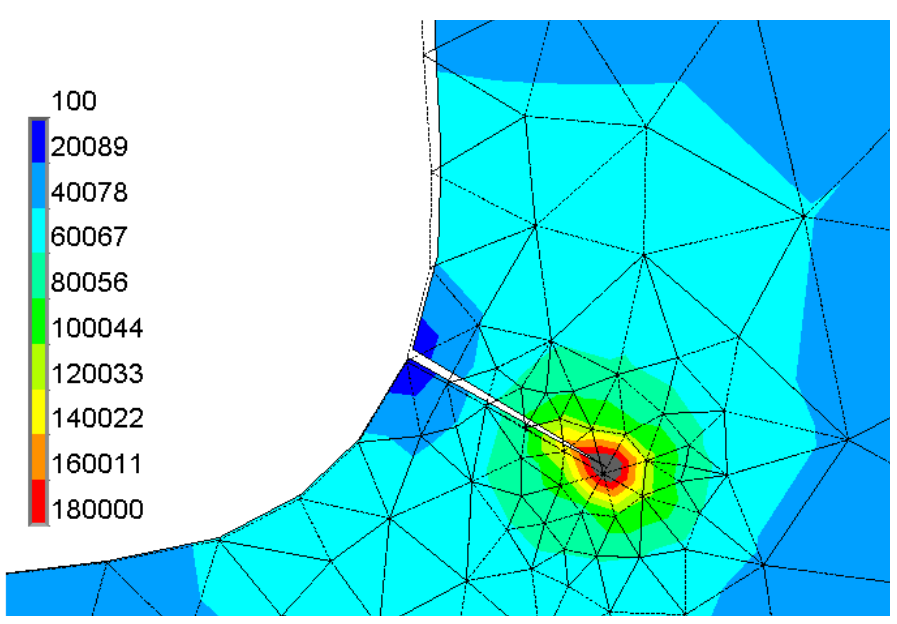

(b)

Figure 3.-Exaggerated deformations and contours of equivalent stress (psi). (a) Notch. (b) Crack.
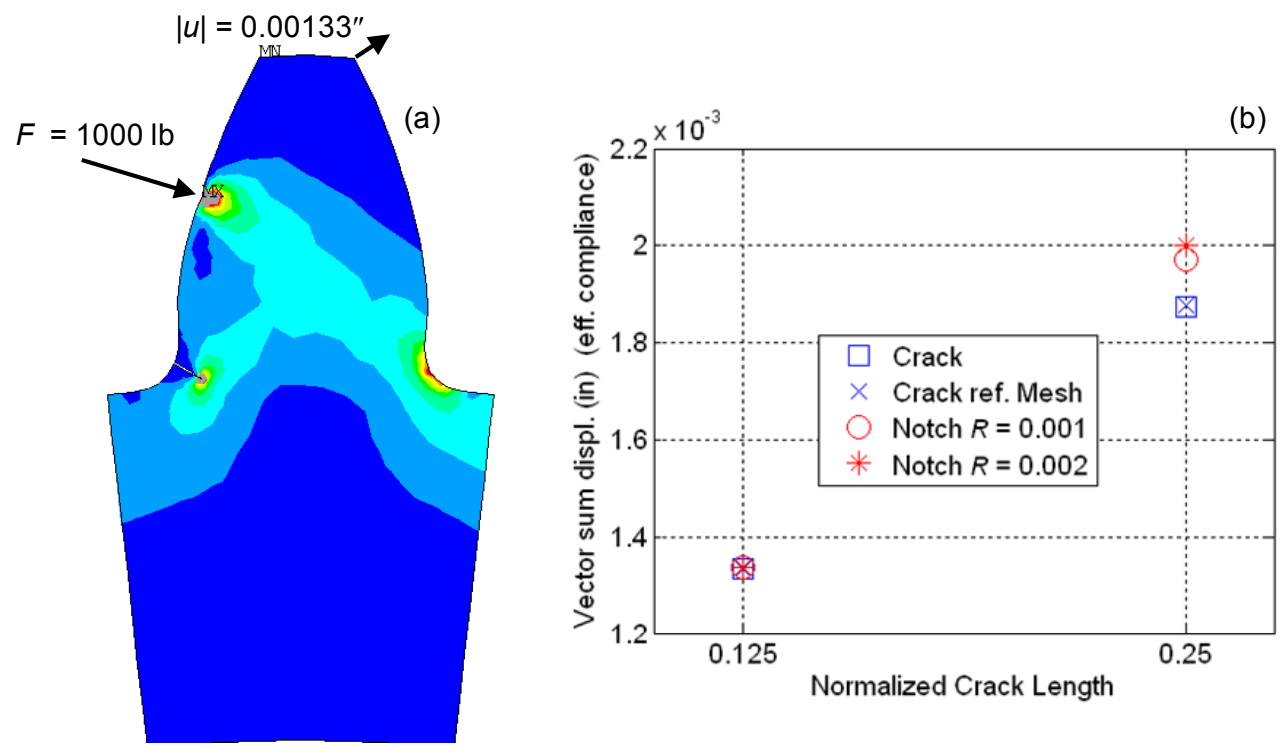

Figure 4.-Static analysis. (a) Annotated contours of equivalent stress. (b) Plot summary of displacements versus crack length. 
TABLE 1.-FEM DISPLACEMENTS (in.) OF CRACKED AND NOTCHED GEAR TEETH

\begin{tabular}{|c|c|c|c|c|}
\hline \multirow{2}{*}{$\begin{array}{l}\text { Normalized } \\
\text { crack length }\end{array}$} & \multicolumn{2}{|c|}{ Crack } & \multicolumn{2}{c|}{ Notch } \\
\cline { 2 - 5 } & Regular mesh & Refined mesh & $R=0.001$ in. & $R=0.002$ in. \\
\hline 0.125 & $1.33420 \mathrm{E}-03$ & $1.33530 \mathrm{E}-03$ & $1.33620 \mathrm{E}-03$ & $1.33660 \mathrm{E}-03$ \\
\hline 0.25 & $1.87280 \mathrm{E}-03$ & $1.87740 \mathrm{E}-03$ & $1.97050 \mathrm{E}-03$ & $2.00100 \mathrm{E}-03$ \\
\hline
\end{tabular}

TABLE 2.-FUNDAMENTAL FREQUENCY (Hz) OF NOTCHED AND CRACKED GEAR TEETH

\begin{tabular}{|c|c|c|c|c|}
\hline \multirow{2}{*}{$\begin{array}{l}\text { Normalized } \\
\text { crack length }\end{array}$} & \multicolumn{2}{|c|}{ Crack } & \multicolumn{2}{c|}{ Notch } \\
\cline { 2 - 5 } & Regular mesh & Refined mesh & $R=0.001$ in. & $R=0.002$ in. \\
\hline 0.125 & $3.02100 \mathrm{E}+03$ & $3.02100 \mathrm{E}+03$ & $3.00200 \mathrm{E}+03$ & $2.98900 \mathrm{E}+03$ \\
\hline 0.25 & $2.56700 \mathrm{E}+03$ & $2.56300 \mathrm{E}+03$ & $2.54500 \mathrm{E}+03$ & $2.52400 \mathrm{E}+03$ \\
\hline
\end{tabular}

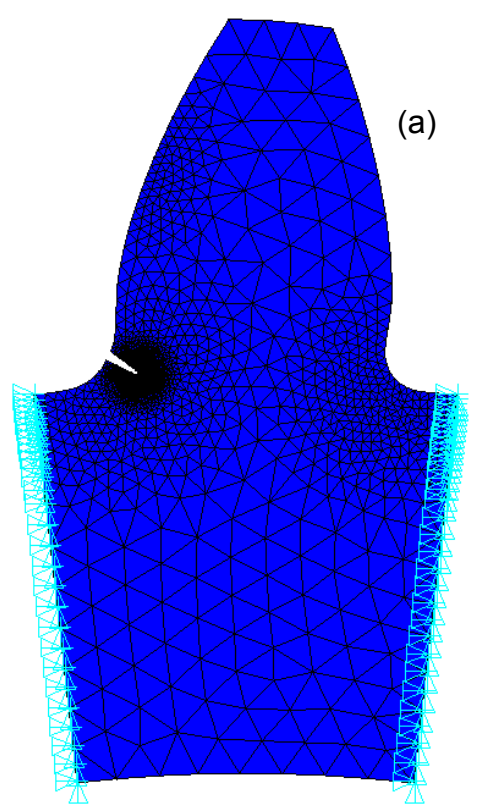

(a)

(b)

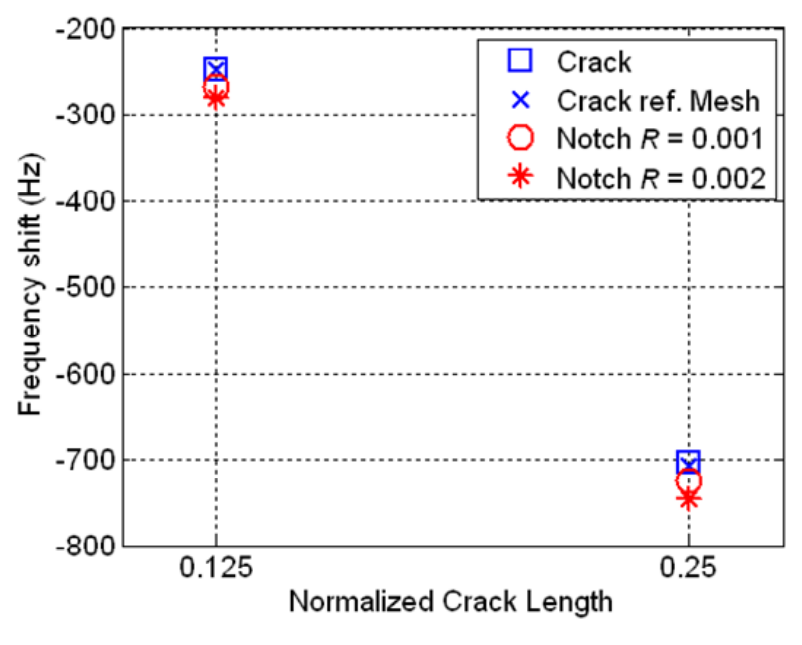

Figure 5.-Modal analysis. (a) Fundamental mode shape. (b) Summary of fundamental frequencies.

An alternative metric for comparison of cracked and notched teeth is the fundamental natural frequency of a gear tooth. Figure 5(a) shows the fundamental mode shape of the gear section of interest associated with the fundamental natural frequency. The fixed boundary conditions are indicated.

Table 2 and Figure 5(b) summarize the FEA results of the modal analysis. Table 2 shows the actual frequencies, while Figure 5(b) shows the frequency shifts from the baseline case, where the baseline is a healthy gear. The frequency decreases as the crack/notch grows. The notches give rise to the larger shifts, but the difference between the notched and cracked teeth is small.

Overall, the analysis shows that a crack and notch of the same length agree very well. Although by a small amount, notched gears exhibit more change in effective compliance and frequency shifts than their cracked counterparts. Thus, it is expected that a vibration feature is slightly more sensitive to the notched tooth than to the cracked tooth. 


\section{Crack Initiation Fixture and Crack Initiation Process}

The cracks were initiated on a commercially available fatigue tester. A special fixture, shown in Figure 6, was designed, developed, and built for this purpose. The fixture captures a single gear between two steel plates and uses an anvil to assert a load on to a single tooth. The gray anvil holder, shown in Figure 6(a), is inserted into the machine's lower ram and secured using a pin. The anvil is held within the anvil holder and captured with two set screws. The anvil width is greater than the gear tooth width and the anvil material is made of tool steel for strength. The anvil gear tooth interface is $5^{\circ}$ with respect to horizontal, similar to the ASME J1619 single tooth fatigue test fixture (Ref. 8). To provide the contact area near the high point of single tooth contact (HPSTC), the centerline of the gear tooth under test is located at $15.4^{\circ}$ with respect to the ground; see Figure 6(c). The gear is located between the 1 in. thick steel plates with a 1.181 in. diameter shaft locating the center of the gear. Keys were used to position the gear teeth with respect to polar angle. The primary device to react the input torque to the gear, however, was three internal gear teeth, shown in brown below, and three fasteners to provide clamping friction. Interfacing with several points within the fixture to transfer the input torque to the machine prevented damage to gear teeth not under test. The two side plates were fastened together and then bolted to a bottom subplate. This subplate was threaded and welded to a connecting rod, shown in red that threaded into the load cell on the fatigue tester.

The fatigue tester operated in load control mode with a cyclic compressive load between 100 and $3100 \mathrm{lb}$ applied at a rate of $10 \mathrm{~Hz}$. The crack initiation region (tooth root) was always held in tension during the test.

A compliance-based feature was developed for early detection of cracks, since the displacementbased feature did not have sufficient resolution. The crack detection is based on observation of $N$ estimations of the feature. We compute the described feature in $N$ points. The first $N-M$ points are used to establish the baseline distribution of the feature, and the last $M$ points are used for determining if the crack occurred. The crack detection is then based on the likelihood ratio as follows

$$
\Lambda=\prod_{k=N-M+1}^{N} \frac{\operatorname{Pr}\left[c_{k} \mid H_{1}\right]}{\operatorname{Pr}\left[c_{k} \mid H_{o}\right]}
$$

where $H_{o}$ is the null hypothesis that states that there is no crack, i.e., the feature is distributed according to the distribution of a healthy gear

$$
H_{o}: c_{k} \sim \mathcal{N}\left(\mu_{c}, \sigma_{c}\right)
$$

$\mu_{c}$ and $\sigma_{c}$ are sample mean and standard deviation of the feature, excluding the last $M$ points.

$$
\begin{gathered}
\mu_{c}=\frac{1}{N-M} \sum_{k=1}^{N-M} c_{k} \\
\sigma_{c}=\frac{1}{N-M-1} \sum_{k=1}^{N-M}\left(c_{k}-\mu_{c}\right)^{2}
\end{gathered}
$$

The alternative hypothesis states that the crack has occurred, that is, the feature $c_{k}$ does not belong to the baseline distribution, but to a normal distribution centered around threshold $\theta$

$$
H_{1}: c_{k} \sim \mathcal{N}\left(\theta, \sigma_{c}\right)
$$



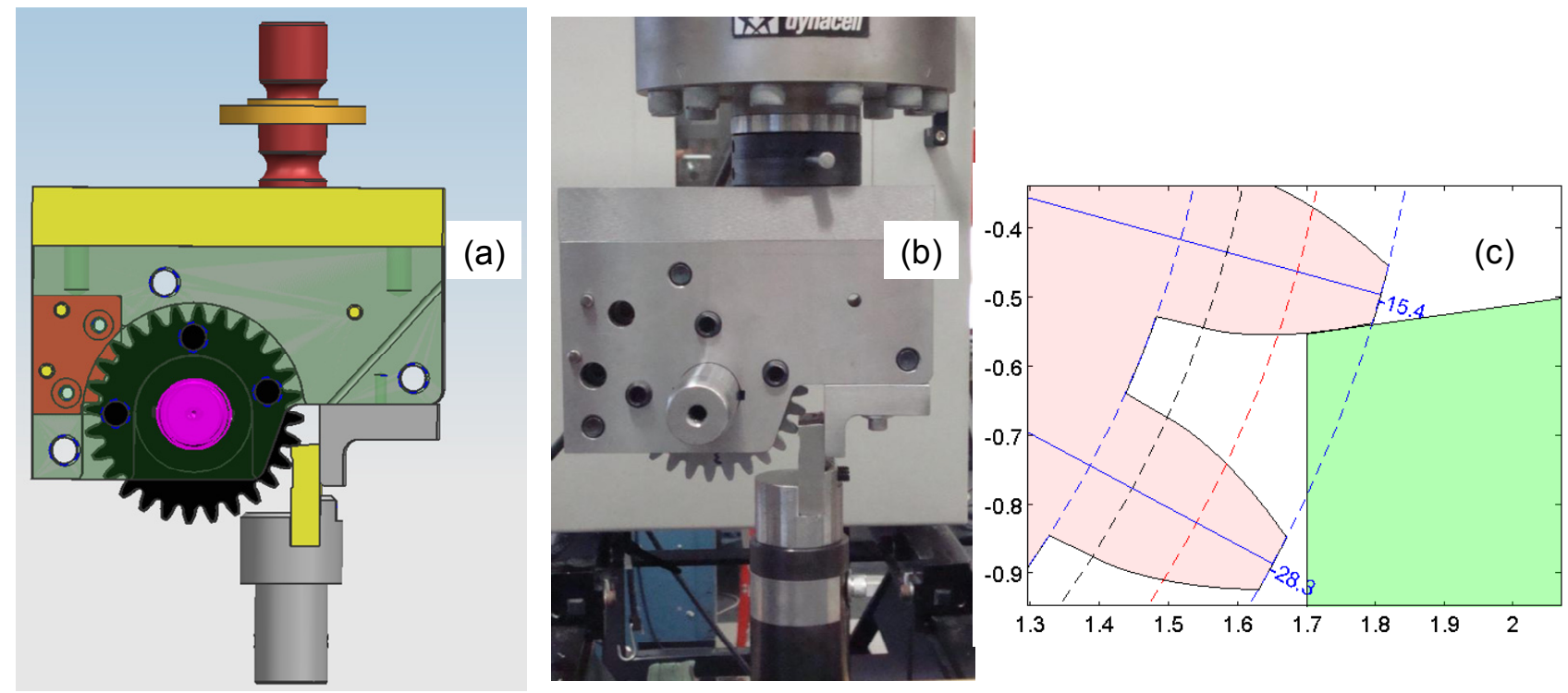

Figure 6.-The fixture for crack initiation. (a) Computer aided design image. (b) Photograph of the built fixture. (c) Anvil angle detail.
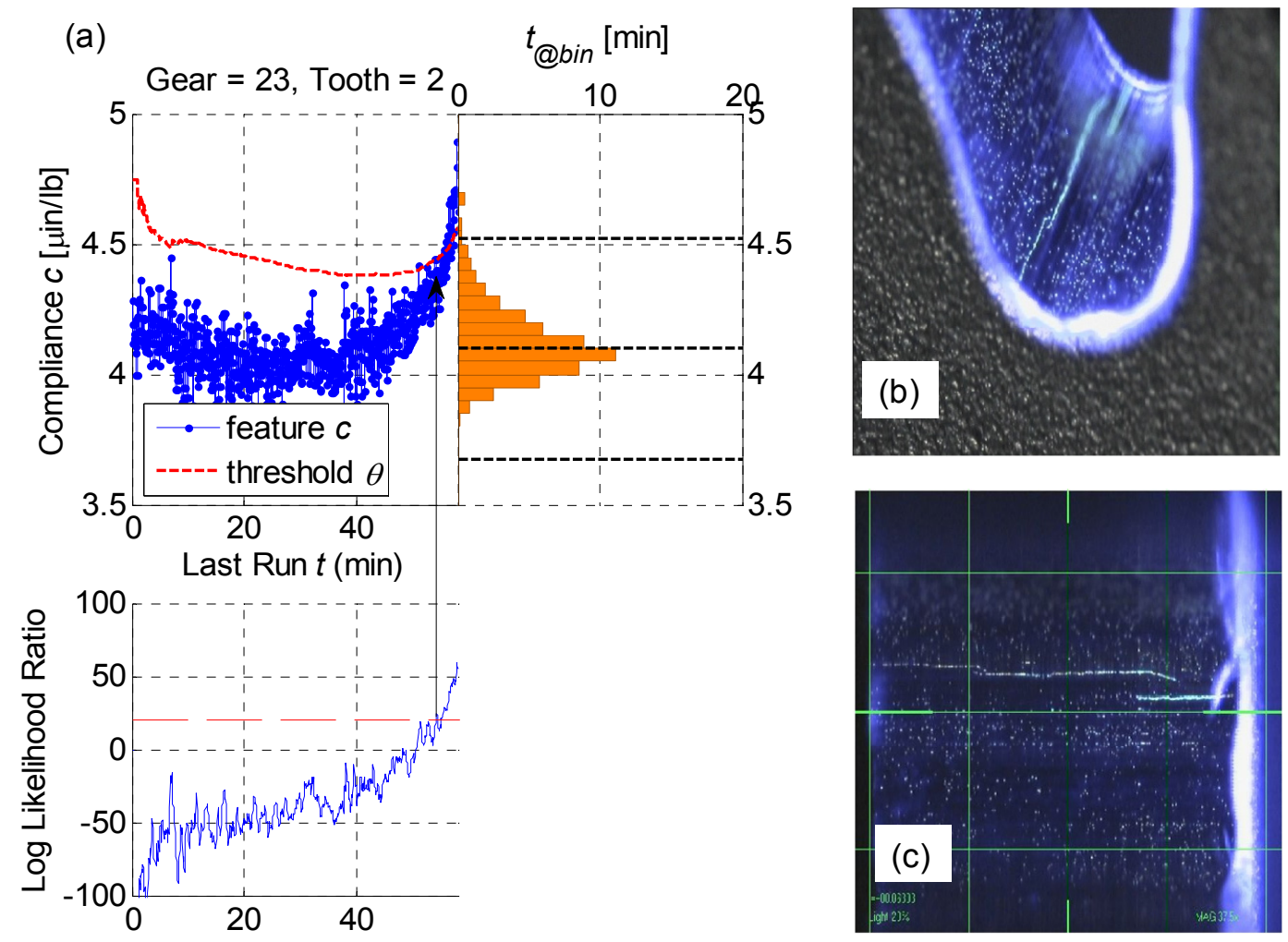

Figure 7.-Crack detection process. (a) Characteristic signals. (b) Angled view of a cracked tooth. (c) $90^{\circ}$ view of a cracked tooth.

Figure 7 depicts the process of crack detection. The compliance feature and the threshold are shown, as well as the distribution of the compliance feature. The threshold is set initially at a conservative, empirically determined, relatively high value. As more data becomes available, the threshold is adjusted to become a certain Mahalanobis distance from the distribution mean. The distance equals to $2.5 \sigma_{c}$ for the example shown in Figure 7(a). 

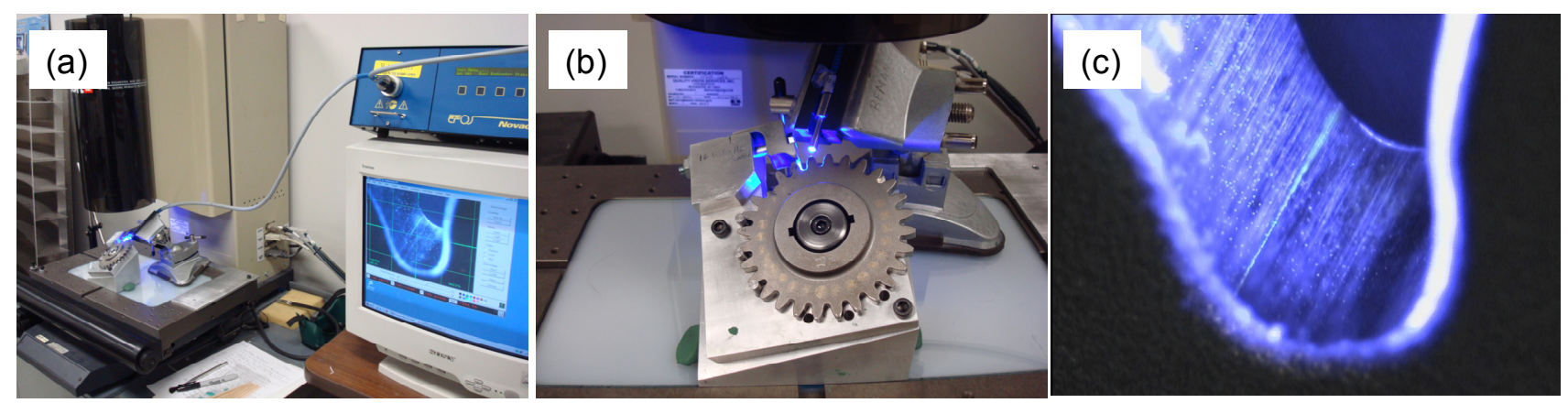

Figure 8.-Nondestructive method for crack verification. (a) Imaging system. (b) Custom gear fixture. (c) Imaged tooth.

\section{Crack Verification Using Nondestructive Methods}

The nondestructive crack verification is based on the images taken using a commercially available high-resolution, optical video measuring system and custom fixture shown in Figure 8. The custom fixture was designed and built to place the test tooth in approximately $500 \mathrm{lb}$ tension. Before the gear is placed in the fixture, the tooth under inspection is covered with a layer of fluorescent iron powder. The tooth is then placed in a strong magnetic field and observed under ultraviolet (UV) light. At a crack, the magnetic lines are disturbed. The magnetic-particle-based inspection method is a standard technique for crack detection and it is described in fracture mechanics textbooks, e.g., (Ref. 9). Glowing particles indicate fracture site.

Figure 8 illustrates the nondestructive measurement process. Prior to imaging the tooth had been subjected to approximately 29 thousand cycles of load in the 100 to $3100 \mathrm{lb}$ range. The final resulting threshold for the compliance feature was $4.40 \mu \mathrm{in} . / \mathrm{lb}$. The tooth was imaged $37.5 \times$ magnification.

This nondestructive method was not completely successful in detecting gear tooth cracks. The gear face area was the only region where cracks could be observed. The gear flank surface was considerable rougher. Even after polishing, no cracks were detected on the gear flanks.

\section{Crack Characterization Using Destructive Methods}

The nondestructive inspection method was useful for confirmation of the crack initiation, but did not allow crack characterization, that is, determination of the actual crack depths. Two methods are described for measuring crack depth and characterization of the fracture surface: slicing and polishing (Method 1) and abruptly breaking teeth off after the initiation (Method 2). Figure 9 illustrates both methods. Cracks were initiated on several different teeth then inspected using both methods. The teeth in the top of Figure 9 were inspected using Method 1 and the three teeth in lower left corner were subjected to the ramped load on the fatigue tester until they fractured based on Method 2.

Method 1 employed a wire EDM to first section a number of previously tested teeth from the gear. The sectioned teeth were then sliced perpendicularly to the initial cut. The slices were polished, etched with an alcohol/nitric acid solution, and imaged with a standard metallographic microscope. Figure 10 shows the gear slices as well as images of polished sections of a tooth demonstrating crack length differences throughout the tooth thickness. The depth of gear tooth crack propagation was 1 to $1.5 \mathrm{~mm}$ in this example. 


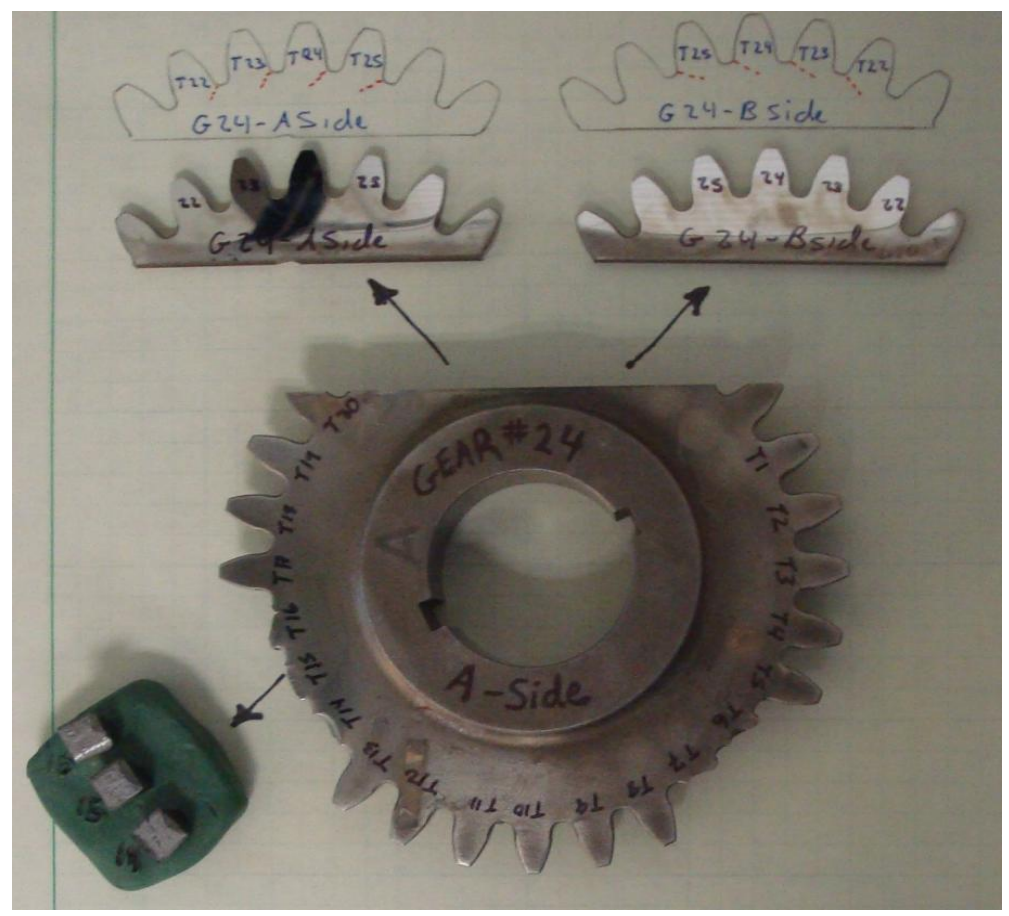

Figure 9.-Destructive inspection of gear tooth cracks.
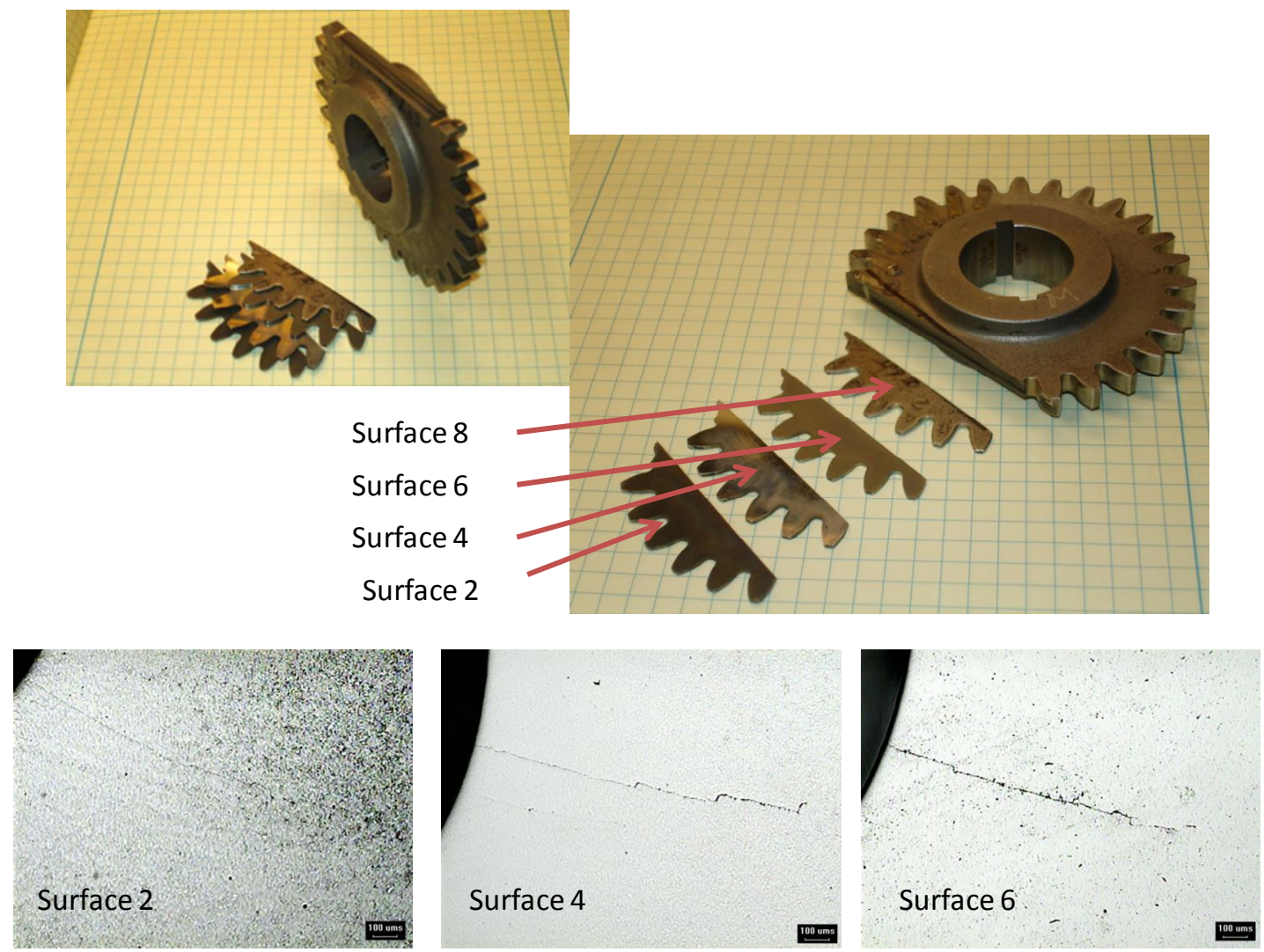

Figure 10.-Destructive inspection using Method 1. 
Method 2 was relatively straight forward. After crack initiation, the test tooth was imaged with the fluorescent iron powder, returned to the fatigue fixture, and the static load increased until fracture resulted. The fracture surfaces were then imaged with a stereo microscope at 24 and $66 \times$ magnification. Figure 11 shows crack surfaces of four different teeth (all teeth imaged from the bottom). There is a clear, discernable boundary that separates the smooth surface of crack initiation from the rough surface of the abrupt breakage (see the annotation in Figure 11(b)). For the various gear tests, the crack depths in the middle of the tooth were consistent with imaging obtained using Method 1 and shown in Figure 10. However for some tests, the crack depths were virtually zero near the gear faces. It was clear that the crack profiles for these cases were significantly different than surfaces produced by notching, which have a uniform depth across the thickness of the gear. We have observed that generally as cracks propagate, the crack depth becomes more uniform across the gear thickness. Thus, for deeper cracks it is reasonable that the crack surface approaches an expected notch surface. This finding also suggests that the compliance change used for crack initiation detection as previously described will be different for notched teeth as compared to cracked teeth when the crack/notch depth is small. Method 2 was considerably more effective, far less labor intensive, and provided an immediate view of the entire crack surface as compared to Method 1. Method 1, in addition to being more laborious and requiring interpolation to visualize entire crack surface, suffered from a fundamental drawback. The wire EDM process affected crack propagation to an unknown and difficult to quantify degree. The advantage of Method 2 was that it was able to show details of the crack shape in the direction of the propagation, as shown in Figure 10.

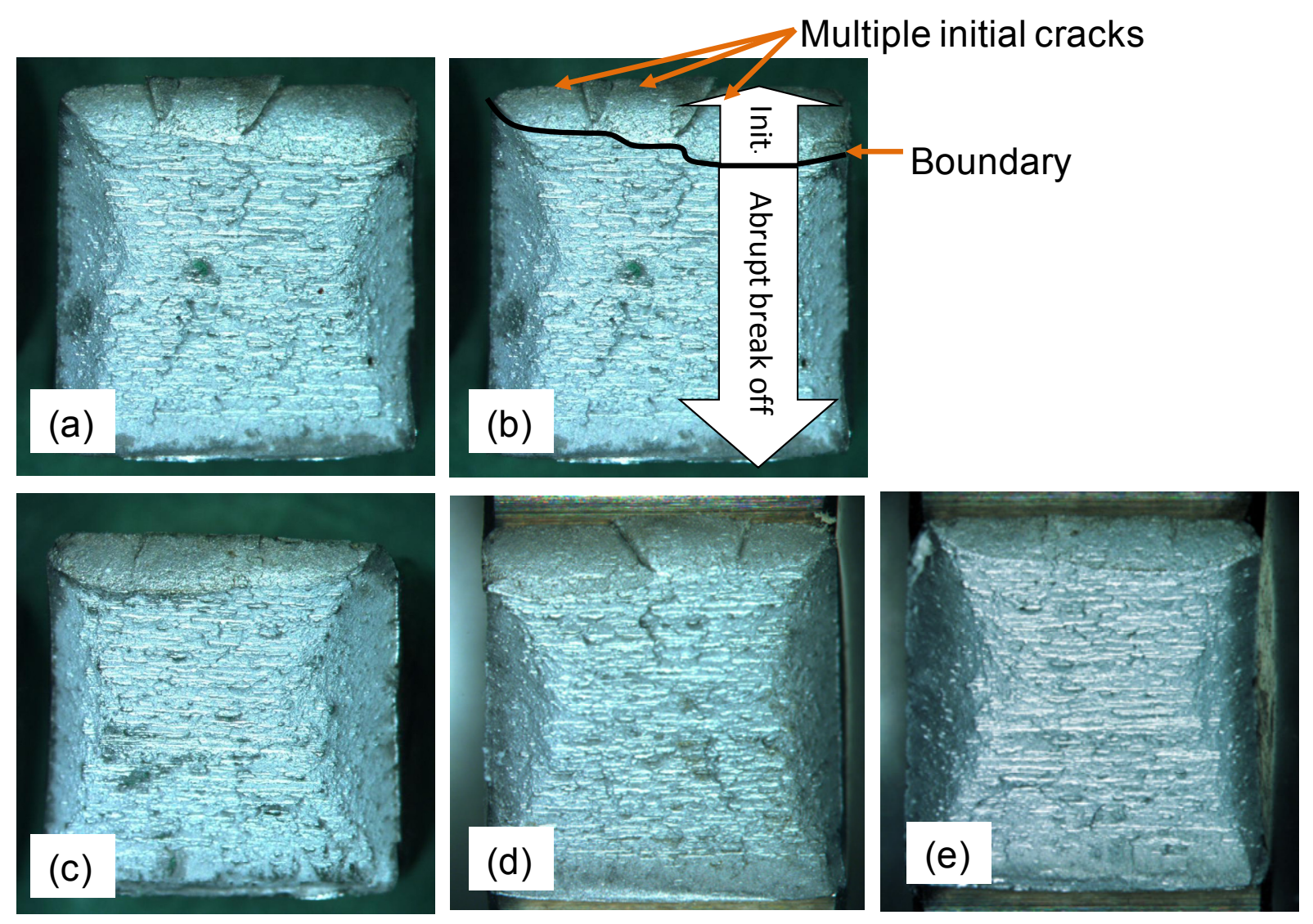

Figure 11.-Destructive inspection using Method 2. 


\section{Summary}

This paper describes an accelerated crack initiation where a selected tooth is subjected to cyclic bending on a fatigue tester. This method of seeding cracks is related to the traditional method (notching) using FEA. FEA compares effective compliance and change in fundamental natural frequencies between a cracked gear tooth and a notched gear tooth, where the notch and the crack are of the same length and of uniform depth. Both metrics consistently show that their dependence on the length of the crack/notch is considerably higher than the dependence on the type of damage. The analysis suggests a plausible conclusion that a cracked and a notched tooth will exhibit very similar vibration features for a given length of crack/notch.

The fixture for crack initiation and the associated process are described, including a compliancebased feature for crack detection. The induced cracks were verified using a nondestructive methods and characterized using the destructive methods. While the nondestructive methods indicate minimal damage to the tooth, closer (destructive) inspections show that the crack surface is somewhat irregular initially and that the maximum depth of crack propagation can be appreciable at the point of detection by the suggested feature.

\section{References}

1. Zakrajsek, J.J., and Lewicki, D.G., 1998, "Detecting Gear Tooth Fatigue Cracks in Advance of Complete Fracture," Tribotest, 4(4), pp. 407-422.

2. Lebold, M., Mcclintic, K., Campbell, R., Byington, C., and Maynard, K., 2000, "Review of Vibration Analysis Methods for Gearbox Diagnostics and Prognostics," Proc. 54th Meeting of the Society for Machinery Failure Prevention Technology, Virginia Beach VA, pp. 623-634.

3. Samuel, P.D., and Pines, D.J., 2005, "A Review of Vibration-Based Techniques for Helicopter Transmission Diagnostics," Journal of Sound and Vibration, 282(1-2), pp. 475-508.

4. Glodez, S., Sraml, M., and Kramberger, J., 2002, "A Computational Model for Determination of Service Life of Gears," International Journal of Fatigue, 24(10), pp. 1013-1020.

5. Hefeng, B., Savage, M., and Knorr, R.J., 1985, "Computer Modeling of Rack-Generated Spur Gears," Mechanism and Machine Theory, 20(4), pp. 351-360.

6. Persson, P.O., and Strang, G., 2004, “A Simple Mesh Generator in Matlab,” SIAM review, 46(2), pp. 329-345.

7. Wawrzynek, P.A., 1991, "Discrete Modeling of Crack Propagation: Theoretical Aspects and Implementation Issues in Two and Three Dimensions," Ph.D. Dissertation, Cornell University, 1991.

8. Gasparini, G., Mariani, U., Gorla, C., Filippini, M., and Rosa, F., "Bending Fatigue Tests of Helicopter Case Carburized Gears: Influence of Material, Design and Manufacturing Parameters."

9. Broek, D., 1986, Elementary Engineering Fracture Mechanics, M. Nijhoff; Distributors for the U.S. and Canada, Kluwer Academic, Dordrecht; BostonHingham, Mass., U.S.A. 


\begin{tabular}{|c|c|c|c|c|c|}
\hline \multicolumn{5}{|c|}{ REPORT DOCUMENTATION PAGE } & $\begin{array}{c}\text { Form Approved } \\
\text { OMB No. 0704-0188 }\end{array}$ \\
\hline \multicolumn{6}{|c|}{$\begin{array}{l}\text { The public reporting burden for this collection of information is estimated to average } 1 \text { hour per response, including the time for reviewing instructions, searching existing data sources, gathering and maintaining the } \\
\text { data needed, and completing and reviewing the collection of information. Send comments regarding this burden estimate or any other aspect of this collection of information, including suggestions for reducing this } \\
\text { burden, to Department of Defense, Washington Headquarters Services, Directorate for Information OPerations and Reports (0704-0188, } 1215 \text { Jefferson Davis Highway, Suite } 1204 \text {, Arlington, VA } 22220-4302 \text {. } \\
\text { Respondents should be aware that notwithstanding any other provision of law, no person shall be subject to any penalty for failing to comply with a collection of information if it does not display a currently valid OMB } \\
\text { control number. } \\
\text { PLEASE DO NOT RETURN YOUR FORM TO THE ABOVE ADDRESS. }\end{array}$} \\
\hline \multicolumn{2}{|c|}{$\begin{array}{l}\text { 1. REPORT DATE (DD-MM-YYYY) } \\
01-02-2011\end{array}$} & \multicolumn{3}{|c|}{$\begin{array}{l}\text { 2. REPORT TYPE } \\
\text { Technical Memorandum }\end{array}$} & 3. DATES COVERED (From - To) \\
\hline \multirow{3}{*}{\multicolumn{5}{|c|}{$\begin{array}{l}\text { 4. TITLE AND SUBTITLE } \\
\text { Seeding Cracks Using a Fatigue Tester for Accelerated Gear Tooth Breaking }\end{array}$}} & 5a. CONTRACT NUMBER \\
\hline & & & & & 5b. GRANT NUMBER \\
\hline & & & & & 5c. PROGRAM ELEMENT NUMBER \\
\hline \multirow{3}{*}{\multicolumn{5}{|c|}{$\begin{array}{l}\text { 6. AUTHOR(S) } \\
\text { Nenadic, Nenad, G.; Wodenscheck, Joseph, A.; Thurston, Michael, G.; Lewicki, David, G. }\end{array}$}} & 5d. PROJECT NUMBER \\
\hline & & & & & 5e. TASK NUMBER \\
\hline & & & & & $\begin{array}{l}\text { 5f. WORK UNIT NUMBER } \\
\text { WBS } 877868.02 .07 .03 .01 .01 .01\end{array}$ \\
\hline \multicolumn{5}{|c|}{$\begin{array}{l}\text { 7. PERFORMING ORGANIZATION NAME(S) AND ADDRESS(ES) } \\
\text { National Aeronautics and Space Administration } \\
\text { John H. Glenn Research Center at Lewis Field } \\
\text { Cleveland, Ohio 44135-3191 }\end{array}$} & $\begin{array}{l}\text { 8. PERFORMING ORGANIZATION } \\
\text { REPORT NUMBER } \\
\text { E-17624 }\end{array}$ \\
\hline \multirow{2}{*}{\multicolumn{5}{|c|}{$\begin{array}{l}\text { 9. SPONSORING/MONITORING AGENCY NAME(S) AND ADDRESS(ES) } \\
\text { National Aeronautics and Space Administration } \\
\text { Washington, DC 20546-0001 }\end{array}$}} & $\begin{array}{l}\text { 10. SPONSORING/MONITOR'S } \\
\text { ACRONYM(S) } \\
\text { NASA }\end{array}$ \\
\hline & & & & & $\begin{array}{l}\text { 11. SPONSORING/MONITORING } \\
\text { REPORT NUMBER } \\
\text { NASA/TM-2011-216983 }\end{array}$ \\
\hline \multicolumn{6}{|c|}{$\begin{array}{l}\text { 12. DISTRIBUTION/AVAILABILITY STATEMENT } \\
\text { Unclassified-Unlimited } \\
\text { Subject Category: } 37 \\
\text { Available electronically at http://www.sti.nasa.gov } \\
\text { This publication is available from the NASA Center for AeroSpace Information, 443-757-5802 }\end{array}$} \\
\hline \multicolumn{6}{|c|}{ 13. SUPPLEMENTARY NOTES } \\
\hline \multirow{2}{*}{\multicolumn{6}{|c|}{$\begin{array}{l}\text { 14. ABSTRACT } \\
\text { This report describes fatigue-induced seeded cracks in spur gears and compares them to cracks created using a more traditional seeding } \\
\text { method, notching. Finite element analysis (FEA) compares the effective compliance of a cracked tooth to the effective compliance of a } \\
\text { notched tooth where the crack and the notch are of the same depth. In this analysis, cracks are propagated to the desired depth using } \\
\text { FRANC2D and effective compliances are computed in ANSYS. A compliance-based feature for detecting cracks on the fatigue tester is } \\
\text { described. The initiated cracks are examined using both nondestructive and destructive methods. The destructive examination reveals } \\
\text { variability in the shape of crack surfaces. } \\
\text { 15. SUBJECT TERMS } \\
\text { Cracks; Gear teeth; Crack propagation }\end{array}$}} \\
\hline & & & & & \\
\hline \multicolumn{3}{|c|}{ 16. SECURITY CLASSIFICATION OF: } & $\begin{array}{l}\text { 17. LIMITATION OF } \\
\text { ABSTRACT }\end{array}$ & $\begin{array}{l}\text { 18. NUMBER } \\
\text { OF }\end{array}$ & $\begin{array}{l}\text { 19a. NAME OF RESPONSIBLE PERSON } \\
\text { STI Help Desk (email:help@sti.nasa.gov) }\end{array}$ \\
\hline $\begin{array}{l}\text { a. REPORT } \\
U\end{array}$ & $\begin{array}{l}\text { b. ABSTRACT } \\
\mathrm{U}\end{array}$ & $\begin{array}{l}\text { c. THIS } \\
\text { PAGE } \\
\text { U }\end{array}$ & UU & $\begin{array}{l}\text { PAGES } \\
16\end{array}$ & $\begin{array}{l}\text { 19b. TELEPHONE NUMBER (include area code) } \\
443-757-5802\end{array}$ \\
\hline
\end{tabular}



